\title{
Mi deuda con Ignacio Ellacuría
}

\section{José Ignacio González Faus, San Cugat del Vallés, Barcelona. Centro de Reflexion Teologica, San Salvador, El Salvador.}

Las notas que siguen, redactadas casi a vuelapluma, no pretenden ser una sistematización completa y objetiva del pensamiento de Ellacuría. Sería esa una tarea para la cual no estoy preparado en absoluto.

Lo que sigue es sólo un reconocimiento subjetivo de aquellos puntos en los que me siento influido por Ellacu. Una especie de confesión, que quiere ser un homenaje. Y la toma de conciencia de un influjo que no se ha dado necesariamente en la lectura y el esudio, sino también en el contacto y la conversación.

Presentaré cuatro puntos, y procuraré titularlos con algún eslogan, tomado de títulos o frases del mismo Ignacio.

\section{Cargar, encargarse y hacerse cargo}

El primer punto es de carácter epistemológico, y tiene claras resonancias zubirianas, incluso en su formulación como juego de palabras. Voy a exponerlo a partir de mi reflexión sobre él, y no como una expresión objetiva del pensamiento de X. Zubiri, que no conozco suficienteriente.

Se trata para mi que todo conocimiento (todo "hacerse cargo" de la realidad) está profundamente implicado con una responsabilidad ("encargarse" de la realidad) y con una pasión o sufrimiento ("cargar" con la realidad).

La interacción entre los tres factores es siempre murua, y no es necesario que el nivel epistemológico tenga siempre la prioridad. También pueden servir para dibujar una ética de la responsabilidad (para encargarse seriamente de la realidad es preciso hacerse cargo de ella y cargar con ella), o una auténtica mística del dolor (para cargar cristianamente con la realidad es preciso hacerse cargo y encargarse de ella). 
Voy a fijarme, no obstante, en el enfoque epistemológico, que vincula el logos al ethos y al pathos. No hay aqui una mera "contaminación marxista", sino la recuperación de una síntesis que está muy presente en la Biblia y que va desde el significado veterotestamentario del verbo "conocer" (referido al acto sexual hecho en un contexto de plenitud y no de frivolidad), hasta la sorprendente relación que establece el cuarto evangelio entre ha obras que se hacen y la luz con la que se ve (vg. Jn 3, 20ss).

De acuerdo con ello, el "hacerse cargo" de la realidad comporta una concepción del conocer más profunda que la mera acumulación objetiva de datos. Las mismas expresiones castellanas como " $i$ ahora me hago cargo!", o "hazie cargo", aluden a una comprensión que va mucho más alua de la mera intelección objetiva, y que vincula conocimiento y empatia. Hay aqul una diferencia clara tanto con la razón moderna como con la mentalidad postmodema, que me gustaría subrayar un poco más.

La moderna "razón instrumental" ha querido hacerse cargo de la realidad sin responsabilizarse de ella y sin soportarla. Casi diriamos más bien que ha intentado conocer la realidad para poder desentenderse de ella y para no tener que soportarla. El resuleado ha sido lo que hoy denuncian en un campo los ecologistas, y antano denunciaban en otro campo los marxistas: la realidad como "presa" y el otro como "objeto" han llevado al hombre a una forma falsa de conocer que hoy se vuelve contra él. Y los mismos medios técnicos, que el hombre se ha creado de esta manera, son los que hoy le impiden ser hombre, porque le impiden tener "un hogar" y le impiden tener "unos hermanos" ("mundo sin hogar", "guerra de lodos contra $\operatorname{codos}^{\prime} .$. son las definiciones de la realidad que brotan de la razón modema).

Pero hay lambién en la epistemología de Ellacu una crítica de la razón "posumodema", la cual ha reaccionado, sí, contra esa visión de la realidad como presa o contra esa objetivación del otro, pero para renunciar a toda totalización de los tres niveles, fragmentándolos y desligándolos uno del otro, en un "pensamiento débil", que comporta a la vez una responsabilidad débil y un amor débil. $Y$ que termina llevando a un individualismo sin subjetividad o sin personalidad.

Todas las críticas de Ignacio al sistema, al país, y al mundo en que viva se explican, en mi opinión, a partir de esta interacción. Su razón no funciona como un cáncer que sólo vive para sí y, con ello, tras un crecimiento asombroso, acaba liquidándose a sf mismo junto con el entomo en el que vivfa y que él mismo había consumido. Su razón era una razón al servicio de algo. Y ese algo nos viene dado por los otros dos niveles: el encargo que la realidad constituye para el hombre, y la empatía que lleva a cargar con la realidad de los demás. Y esto mismo lo formulaba otro de los principios acufiados por Ellacuria: la razón 
al servicio de la revolución.

\section{La razón al servicio de la revolución}

Si se lo quiere formular más bíblicamente (o si a alguien le molesta la palabra "revolución" y le suscita unas imágnes violentas que incomprensiblemente, no le suscita la palabra "orden"), entonces podemos hablar sencillamente de la razón al servicio de la metanoia, al servicio de esa conversión total que constituye el reverso del reinado de Dios.

Lo que implica la fórmula de Ellacu es la profunda convicción que le acompaftaba, que ese maravilloso instrumento que es la razón humana (y que en él alcanzó cotas llamativas) esta, sin embargo, enfermo y necesita ser sanada. He conocido pocas personas más razonadoras (casi dirfa más racionalistas) que Ignacio. Y, sin embargo, nadie más convencido que êl de la imposible neutralidad de toda razón.

Yo mismo escribí en otro momento, comentando está convicción de Ellacuría, que el hombre no es, como se nos quiere hacer creer, un animal racional, sino más bien un animal "que racionaliza", es decir, que justifica. Y que utiliza la propia razón no para abrirse a lo universal, que es lo común a todos los hombres, sino para universalizar la propia parcialidad, el propio interés, la propia limitación y, de este modo, imponerse sobre los demás. La razón se convierte entonces en un amma excepcional, pero en manos de un delincuente; o en un fármaco prodigioso, pero en manos de un drogadiclo. Y recuerdo haber comentado un día con él como la gran tragedia de Marx (más allá del valor de sus análisis económicos que él comparía) habla sido su fe ingenua en la universalidad de la razón. Marx constató que la religión era incapaz de crear universalidad y fraternidad entre los hombres, porque los dioses son como las monedas, que son diversas, y sollo tiene valor dentro de las propias fronteras. La religión sólo ha producido guerras de religión. Y frente a eso clamaba Marx: "¿no hay una naturaleza humana universal, así como existe una nawraleza universal de las plantas y de los cuerpos celetes? ¿Tienes que creer en algún país que $3 \times 1=17$ ? Las verdades metafísicas de la filosofía no conocen los límites de la geografla polícica. Porque la filosoffa pregunta qué es la verdad para todos los hombres, no qué es la verdad para los individuos"... La consecuencia de este modo de argumentar (inesperada para Marx) ya la conocemos nosotros: a las guerras de religión han seguido las "guerras de razón". Porque casi todas las dicladuras modernas, como el conflicto este-oeste y, mucho más, el conflicto norte-sur son "guerras de razón", que están durando ya más que aquella famosa guerra religiosa "de los treinia años".

$Y$ visla la repetición del fracaso se impone la conclusión que su causa no radicaba en la religión ni en la razón como tales, sino en el hombre que las utiliza. Es éste el que necesila converuir su razón y converir su religiosidad (o 
mejor: convertirse él hasta esos niveles tan profundos de la persona), poniéndolas al servicio de la verdadera universalidad, y sacándolas de la esclavitud de la falsa universalización de sI mismo.

Pero la razón no podrá recuperar su verdadera universalidad si no incluye a (y si no parte de) todos aquellos a quienes se les ha negado la razón: todos los pobres y los condenados de la tierra. No sólo porque es imposible que éstos queden incluidos en una afimnación genérica y formal de universalidad, sino porque ellos son, además, la mayoría del planeta

Y aquí reside el sentido universal de la "opción por los pobres" tal como la solfa explicar Ellacurfa: no hace falta andar matizando esa expresión (discutiendo si es excluyente o no lo es). Más bien hay que comprender que decir "opción por los pobres"; es la única manera que cabe en este mundo para decir "opción por todos". Y que toda otra fórmula será sólo una fórmula falsamente universal, que habrá justificado y racionalizado la absolutización de una parcialidad.

Este era el meollo de algunos de los enfrentamientos de Ellacuría con los teólogos progresistas europeos, a los que él acusaba a veces de "eurocéntricos". Pero ahora me gustaría subrayar que, en contra de lo que muchos dijeron interesadamente, éste era también el núcleo de sus diferencias con Marx: porque Ellacu habló siempre de una razón al servicio de la revolución; no de una razón que se erige en representante o en propietaria de la revolución. Esto último fue el error de Marx o, por lo menos, de muchos de sus seguidores. $Y$ las diferencias de resultados son bien palmarias: el marxismo dio lugar a un sistema dominador en nombre de la universalidad de los pobres. Ellacuria (que no se sentía suplantador, ni representante, ni propietario, sino sólo servidor de los pobres) dio lugar a un discurso al que sus enemigos no encontraban manera de rebatir. Por eso no les quedó más remedio que matarlo, y matarlo con rabia.

Y cualquier razón no empecatada podrá reconocer que, en esto, el destino de Ellacuria se parece al destino de Jesús de Nazaret, y no al de Carlos Marx.

\section{Iglesia sacramento "histórico" de salvación}

En el concilio Vaticano II, la Iglesia renunció a definirse a sl misma como "sociedad perfecta" y se presento ante los hombres como sental o símbolo ("sacramento"). Sacramento de la salvación de Dios y de la unidad de todo el género humano, son las expresiones preferidas por el Vaticano II (LG, ns. 1 y 48).

Se trata de una opción audaz y arriesgada, aunque parezca intrascendente. Al presentarse como "sacramento", la Iglesia se obligaba a volverse significativa, en lugar de impositiva. Aspiraba a obtener la audiencia de los hombres a partir de lo que ella significa para ellos, y no a partir de apelaciones a una "autoridad 
exterior" que le habría sido dada. Al renunciar a definirse como "sociedad perfecta", la Iglesia aspiraba a confiar más en el "instinto interior" con que el Espíritu de Dios mueve la libertad de todos los hombres, que no en la imposición desde arriba y en el temor que ésta genera.

Tan seria era esa opción que, a mi parecer, casi toda la crisis posterior al Vaticano Il podría explicarse a partir de ahí, por la tensión entre una serie de fuerzas que aspiraban simplemente a convertir la Iglesia en "sacramento", es decir, a hacerla significativa para los hombres (aunque a veces lo hiciesen de una manera reductiva y olvidando el destino del crucificado), y un poder central, romano, que se daba cuenta de que el converirse en sacramento le quitaba dominio y poder.

Pero este ejemplo ha sido puesto sólo para mostrar hasta qué punto la opción del Vaticano II era importante y valiente. Ahora quisiera volver a la aportación de Ignacio Ellacuría.

Ellacuría añade a la fómula del Vaticano II el adjetivo "histórico": la Iglesia es "sacramento histórico de salvación". Con ello sitúa decisivamente el ámbito en el que debe funcionar la significatividad de la Iglesia: en la historia humana y no fuera 0 al margen de ella.

No hay aqui ningún reduccionismo puesto que eso que es significado en la historia humana es, nada menos, que la salvación trascendente. El mismo Ellacu lo formulaba así con su lúcida precisión: la Iglesia "es más que lo que en ella se ve y se puede llegar a ver"; pero esa trascendencia "no estriba en algo misterioso y oculto, sino en algo que supera en la historia a la historia misma, en algo que en el hombre supera al hombre mismo, en algo que obliga a decir: 'verdaderamente se esconde aquí el dedo de Dios'".

No hay pues ningún reduccionismo en la fórmula "sacramento histórico de salvación". Pero sí que hay un intento de evitar una falsificación evasiva de la enseffanza del Vaticano II. Ignacio adivinaba que, en su configuración actual y sin una profunda "conversión de la Iglesia al reino de Dios" (Ĺtulo de otra de sus obras), la Iglesia sólo puede ser sacramento de salvación para dos tipos de gentes:

(a) para los fundamentalistas. Para aquellos que ya están "convencidos de antemano" y que no necesitan la significatividad del signo, porque ellos proyectan sobre él todos los significados que necesitan.

Y (b) para los espiritualistas. Para aquellos que conciben la salvación no como un hacerse-carne de la autocomunicación de Dios (cf. Jn 1, 14), sino como una huida de este mundo. Para aquellos que desean una Iglesia que sea "sacramento de evasión" en lugar de sacramento de salvación. Porque la evasión deja intocadas rodas las realidades de este mundo (el dinero, el poder, el sexo...), mientras que la salvación obliga a convertirlas. 
Este es el valor de la fórmula "sacramento histórico de salvación". Su relevancia práxica comienza en el momento en que los hombres perciben que, una vez abocada la Iglesia a esta historia, no aparece en ella como sacramento de ninguna salvación que toque a la historia, sino más bien como "sacramento del ancien régime" (fórmula que yo mismo emplé en otra ocasión). La expresión de Ellacu entrafta, pues, la exigencia de una profunda conversión de la Iglesia. Y esta exigencia da razón, como ya he dicho, no sólo de las inquietudes y desórdenes postconciliares, sino de las profundas connotaciones eclesiologicas que posee la teología de la liberación, pese a que nunca ha pretendido ser una eclesiología

\section{El pueblo crucificado}

Lo dicho en el apartado anterior ya permite comprender por que Ellacuría llamaba sacramento histórico de salvación propiamente a la Iglesia de los pobres. Pero esto se pone aún más de relieve con el último punto que quisiera comentar: la dimensión cristológica que está insinuada en la expresión "pueblo crucificado".

Cualquier teología del color que sea ha de estar de acuerdo en que la Iglesia sólo puede scr Iglesia del crucificado. Pero esta verdad dogmática se oscurece con frecuencia por la manera como los cristianos hablamos del crucificado. Entre los cristianos es más frecuente hablar de "la cruz" que del "crucificado". El lenguaje del crucificado implica siempre la alusión a alguien que crucifica, y, en definitiva, son los poderes históricos: político, económico y religioso (los romanos, los saduceos y el Sanedrín, que además poseen poder para comprar la complicidad del pueblo mismo). Por otro lado, la fe cristiana en la universalidad de Cristo obliga a extender ese lenguaje sobre el Scñor a lodos los crucificados de la tierra ( $c f$. Mt 25, 31ss) y, con ello, obliga a plantear la pregunta por aquellos poderes que hoy los crucifican.

El lenguaje sobre "la cruz", en cambio, se vuelve más abstracto y menos conflictivo: cualquier tipo de desgracia o mala suerte puede ser llamada "la cruz que me ha cafdo" o "la cruz que el Sefior me envla": desde una enfermedad o un terremoto hasta una operación desafortunada en la bolsa De este modo, Pilatos y Caifás pueden ser alineados junto al crucificado, puesto que tampoco cscapan de esas desgtacias naturales: "los ricos también lloran" decía un culebrón mexicano que puede servir para quitar mordiente a la expresión de Ellacuría. Y la consecuencia ya se adivina: los pobres, por tanto, que se callen.

Quisiera dejar muy claro que, al hacer esta distinción, en modo alguno pretendo insinuar que Jesús (y sus seguidores) no hayan de preocuparse por ayudar a todos los hombres en las desgracias naturales. Solo digo que Jesús, en este último caso, no hablaba de "mi cruz", sino de la "esclavitud de Satanás" ( $c f r$. Lc 13, 16). Una vez aclarado esto hay que afladir que Jesús luchó con todas sus 
fuerzas contra esa esclavitud de Satanás, hasta el punto de proclamar con palabras y con hechos que es más importante liberar a los seres humanos de las esclavindes de Satán, que respetar los espacios sagrados (los sábados) de la hisbria. Tanto que esa lucha le costo la vida.

Pero para este tipo de sufrimientos Jesús no usó el lenguaje de la cruz: precisamente porque se trata de un dolor que sería mucho más posible de vencer para el hombre, si él quisiera dedicar a esta lucha su tiempo y sus recursos, en lugar de destinarlos a elaborar formas cada vez más sofisticadas de placer (o de destrucción de los demás) que conslituyen otra esclavitud de Satán.

En cambio, cuando Jesús anuncia que El Hombre ha de ser desechado y ha de padecer mucho a manos del poder religioso y de los sabios de este mundo ( $c$. Mc 8,31 ), aflade inmediatamente a continuación que el que quiera seguirle ha de "Lomar su cruz a cuestas" (ff. Mc 8, 34). Aqui tenemos el "contexto vital" del lenguaje de la cruz: el crucificado y aquellos que lo crucifican. En fin de cuentas pues, la cruz no consiste primariamente en soportar las inclemencias de la vida, sino en "cargar con el pecado" del mundo.

La genialidad de la fómula de Ellacu ( $y$ de toda la teología de la liberación en este punto), consiste en que, al recuperar el lenguaje del crucificado, recupera también la pregunta por los crucificados de hoy, que hacen presente al Sentor. "El pueblo crucificado" se convirtió aś para él en la encamación de aquel Siervo de Yahvé, sin casi ligura humana y despreciado por los que se consideraban "hombres", pero que estaba llevando los pecados de todos ellos, y por eso contribuía a redimirlos.

Y esta es la última paradoja de la teologla de la liberación, que recupera (quizá sin saberlo) un tema muy querido para los santos padres y para toda la tradición teológica: es gracias a los pobres de la tierra como se salvarán (si es que se salvan) los ricos y los poderosos de este mundo. Porque el lenguaje del "pueblo crucificado" no sugiere ninguna victoria segura sobre los poderes opresores de este mundo, sino que más bien anuncia un destino que a él y a los suyos ya les locó soportar, en seguimiento de Jesús.'

Por eso quiero terminar reconociendo una cosa: la teologia de Ignacio Ellacuría es efectivamente blasfema e idiota. $Y$, de acuerdo con esto, fue quitado de en medio con derecho y con razón. Pero hay que afiadir que es blasferna e idiota para los dioses de este mundo: blasfema para el dios de Caifás y de los saduceos; e idiota para el dios de Pilatos y de Herodes. En cambio, respecto al Dios de Jesús no es blasfemia ni idiotez, sino transparencia y presencia Por eso acabará triunfando, aunque haya sido quitada de en medio violentamente.

Y repito para terminar que lo anterior no ha pretendido ser una exposición global del sistema de Ignacio Ellacuria, sino el comentario a cuatro intruicciones que creo haber aprendido de él, y que él supo formular con esos cuatro túlos 
breves, lúcidos y densos, como solín ser tantas veces sus palabras. 